\title{
CODE OF CONDUCT REGARDING THE PROTECTION OF PERSONAL DATA IN HIGHER EDUCATION - CRITERIA AND PROCEDURES FOR APPROVAL
}

\author{
Zhivka Mateeva \\ Chief Assist. Prof, Ph.D., University of Economics - Varna, Bulgaria, jivkamateeva@ue-varna.bg
}

\begin{abstract}
The Code of Conduct is a new and important instrument explicitly determined by the EU in Regulation (EU) 2016/679 of the European Parliament and of the Council of 27 April 2016 on the protection of individuals with regard to the processing of personal data and on the free operation with such data (General Data Protection Regulation), in order to effectively apply data protection rules to a particular sector or profession. The development and adoption of a code of conduct is not mandatory, but given the economic and social integration and the rapid introduction of digital technologies, leading to a significant increase of the free exchange of personal data, it poses a serious challenge to its protection. Undoubtedly, the protection of personal data has gained cumulative public importance and recognition in recent years, as there is almost no area in modern social, economic and public life in which there is no need to carry out data processing activities. Presented in this context, the development of information technology plays a crucial role in the process of digitalization of the society, including the digitalization in the field of higher education. In regards to the Bulgarian higher education, the pandemic caused by COVID-19 and the measures for self-isolation served as a catalyst: for digitalization and hope for modernization of the educational process. One of the most important aspects of information security for individuals is the protection of personal data, which is part of the right to privacy, which is applicable in higher education. Bulgarian universities should make efforts to adapt to new opportunities and challenges based on the development of digital technologies. As data controllers, higher education institutions fall within the scope of the legal framework for personal data protection and should ensure appropriate levels of data protection through the application of adequate technical and organizational measures. The nature of the data and the huge risk of security breaches require simultaneous implementation of measures according to the General Data Protection Regulation (GDPR) and the adoption of a code of conduct to - ensure the free operation of data, and the confidence and security of the data subjects in education.

The Code of Conduct is a tool that contains a set of internal rules and guidelines for practices that set ethical standards for data controllers and serve as a guide in decision-making. Undoubtedly, the adoption of a code of conduct in the field of higher education is a matter of great practical application. This presentation discusses the criteria and procedures for drafting a code of conduct on personal data protection in higher education in Bulgaria, compliance with the GDPR and the guidelines of the national supervisory authority for Bulgaria this is the Commission for Personal Data Protection (CPDP). Emphasis of its development is placed on the approval of the code of conduct, which is a guarantee for the effective application of the rules for personal data protection in the field of higher education.
\end{abstract}

Keywords: code of conduct, higher education, personal data, national supervisory authority. 


\section{INTRODUCTION}

The legal framework of codes of conduct is contained in Articles 40 and 41 of the General Data Protection Regulation (GDPR). These decrees on codes of conduct are a practical, potentially cost-effective and meaningful method for achieving greater coherence in the protection of data protection rights (European Data Protection Board, 2019, p.5). The usefulness of codes as a reporting tool is that they contribute to the proper application of the GDPR by administrators and processors, belonging to a sector or carrying out similar activities, taking into consideration the specific characteristics of the sector and the needs of the micro, small and medium enterprises, engaged in data processing activities in this sector (ToshkovaNikolova, Feti, 2019, p. 312). Therefore the codes of conduct are appropriate for controllers / processors belonging to the higher education sector, as they provide an opportunity to unify data processing activities and agree on the developed data protection rules for the needs of the sector, in compliance with the GDPR. Moreover, from the point of view of data protection, the Code will serve as a regulation to which the respective higher education institutions - administrators / processors of personal data will adhere in their data processing activities. To this date, there is no code of conduct in the field of higher education. In this regard, the adoption of such will contribute to the achievement of the following main objectives: providing users of educational services a tool for assessing the level of personal data protection in higher education in the country; providing higher education institutions, regardless of their size or profile, with methodological guidelines for assessing and achieving compliance with European and national legislation in the field of personal data; providing higher education institutions with a structured mechanism for demonstrating transparency to supervisors and all other stakeholders in the field of higher education (Prodanov, 2021, p. 175-176).

According to Article 40, paragraph 1 of the GDPR, the Member States, supervisors, the European Data Protection Board (EDPB) and the European Commission are obliged to promote the development of codes of conduct in order to contribute to the proper implementation of the GDPR. The Commission for Personal Data Protection (CPDP), as a national supervisory organization, gives an opinion whether the draft code, its amendment or supplementation comply with the GDPR and, when it determines that it provides sufficient appropriate guarantees, approves it. In this regard, the CPDP should conduct a comprehensive assessment and review of the draft code of conduct. Its evaluation is carried out in accordance with: the decrees of Art. 40 and 41 of the GDPR requirements; and it is also executed according to the criteria under Article 66 in the "Regulations of Proceedings of the Commission for Personal Data Protection and its Administration" (RPCPDPIA). The purpose of these criteria is to clarify the parameters of the GDPR in order to support the singular understanding and application of its requirements in the preparation of codes of conduct. Moreover, these criteria sets out the minimum requirements of the competent supervisory authority with the purpose of conducting an in-depth review and evaluation of the draft code and assist the authorities in the consistent evaluation process. This paper analyzes the criteria and procedures for approving a draft code of conduct in higher education, which is a guarantee for the effective implementation of personal data protection rules.

\section{CRITERIA FOR APPROVAL OF A DRAFT “CODE OF CONDUCT” REGARDING THE PROTECTION OF PERSONAL DATA}

For the purpose of the efficient evaluation and review of each draft code of conduct, upon its approval - the Commission for Personal Data Protection (CPDP) will evaluate the implementation of the following criteria, explicitly stated in Art. 66 of the "Regulations of Proceedings of the Commission for Personal Data Protection and its Administration" (RPCPDPIA):

\section{1) The subject matter, territorial and sectoral scope of the draft code and the specific legal framework for the sector concerned}

The draft code of conduct that is submitted for approval should contain clear information on the sector, subsector or relevant area of public relations to which the administrators, who will implement it, belong to. For example, those responsible for the implementation of a code of conduct in the field of higher education will be the university-administrators / processors of personal data, in relation to their duties. Therefore, the code must specify the exact application of the GDPR for higher education and identify the specific needs of this sector. In order to ensure the required clarity, the code should also specify the duties of the controllers or other common characteristics that associate them, such as: processing activities, categories of controllers / processors, subjects of data collection, categories of personal data, etc. It is essential that the duties of the different administrators are similar, homogeneous. The CPDP considers that the varied operation processes of the administrators is an obstacle to clarifying the application of the GDPR as a whole, in relation to a specific sector (Standpoint of the CPDP, reg. № NDMSPO-01-697 / 27.06.2018). In this sense, the CPDP 
clarifies that the code of conduct has added value only when it is designed specifically for a particular sector or industry, acknowledges its characteristics and existing practices in personal data processing, such as specific risks to the rights and sovereignty of the subjects of data collection and the appropriate technical and organizational measures for their limitation (CPDP. Criteria and procedures for approval, amendment or supplementation of a code of conduct, 2018, p. 1).

\section{2) The criteria and mechanisms for associating controllers / processors of personal data to the draft code}

Compliance to an approved code of conduct is essential for controllers / processors who have acceded to it. On the one hand, it will play the role of an appropriate method by which the controllers / processors of personal data will attest compliance with the GDPR. Moreover, data controllers / processors who have joined the code are obliged to comply with its rules and requirements for the processing of personal data. In cases where controllers / processors carry out other specific processing operations (Yolova, 2021) that are outside the scope of the Code, they should apply the relevant rules to them under the legal framework. Furthermore, adherence to an approved code will be a factor that supervisors will take into account when assessing specific features of data processing, such as security-related aspects, when analyzing the impact of processing according to the data protection impact assessment, and when imposing an administrative fine (European Data Protection Board (EDPB), 2019, p.12). In this regard, the Code of Conduct should be open to access to controllers / processors who belong to the association or other entity that initiated its creation or that have certain similarities that unite them. It should also set out the criteria by which possible association will be considered, as well as the binding obligations of that accession. In addition, the draft code also requires a description of the mechanism for terminating or suspending accession.

\section{3) The mechanism for carrying out mandatory monitoring of compliance with the draft code}

An obligatory condition for the final approval of a code of conduct for non-public administrators / processors of personal data is the presence of a supervisory body within the meaning of Art. 41 of the GDPR. The accreditation of a supervisory body is the last stage of the factual composition of the approval of codes of conduct (Standpoint of the CPDP Reg. № NDMSPO-17-723 / 2018, 22.02.2019). The CPDP has the authority to accredit a supervisory body that has the appropriate level of experience in relation to the subject of the Code. According to Art.14a of the Personal Data Protection Act (PDPA) the conditions, procedure and criteria for approval of codes of conduct are determined by RPCPDPIA, and the requirements for accreditation of a supervisory body in accordance with Art. 41 of the GDPR are determined by a regulation adopted by the commission. When the codes of conduct are of national scope and do not provide for crossborder processing of personal data, the procedure for approval of the code is developed entirely in compliance with the CPDP without the need to apply a coherence mechanism. In other cases, the draft criteria for the accreditation of a supervisory body should be approved by the European Data Protection Board (EDPB) in accordance with the coherence mechanism, according to Article 41, para.3 of the GDPR. In order to ensure transparency regarding the effective territorial scope of the draft code, procedures and mechanisms should be put in place to monitor compliance with its clauses. On the basis of the procedures set out in the Code, the accreditation body shall carry out the obligatory monitoring of the observance of its requirements by the controllers / processors of personal data who have recognized it. In addition, the supervision by the accredited body should be carried out without prejudice to the obligations and powers of the CPDP as a national supervisory authority for personal data protection.

\section{4) The existence of common criteria and mechanisms for performing risk analysis and impact assessment under Art. 35 of the GDPR}

Risk management is a complex and multifaceted activity, the main purpose of which is to reduce risk (Tselkov and other, 2020, p. 91). Conducting a comprehensive and objective risk analysis, that accompanies the processing of personal data, is an important preventive action that can be used as a form of reporting following the principle of "integrity and confidentiality" (Feti, Toshkova-Nikolova, 2020, p.168). In this regard, the development of risk assessment should take into account the specific characteristics of the activities carried out by the higher education institutions (Dimitrova, 2016; Dimitrova, 2020; Andreeva \& Dimitrova, 2021). In cases where a certain type of processing is likely to pose a high risk to the rights and sovereignty of the individuals before processing, the controller shall assess the impact of the planned processing operations on personal data protection, according to Article 35, para.1 of the GDPR. In order to assess the security of processing in the sector concerned, the impact assessment needs to be equitable, not general. In order to ensure the security of processing in the field of higher education, it is necessary for the draft code to contain criteria and mechanisms for risk analysis and impact assessment, as they determine the specific appropriate technical and organizational security measures for data collection. Certainly, the criteria for 
carrying out both the risk analysis and the data protection impact assessment set out in the Code will help to identify general risks regarding processing in higher education, as well as facilitate administrators / processors of personal data on the fulfillment of their individual obligations under the GDPR.

\section{5) Mechanisms to support accountability by providing sample documents}

The draft code of conduct should establish that the related parties will fulfill their obligations in accordance with the GDPR, and in compliance with the principle of accountability. Reporting requires that the controllers / processors of personal data are able to prove that their actions are in compliance with the requirements of the GDPR. In order to ensure accountability, the code of conduct should include sample documents and documentation on risk analysis and impact assessment, technical and organizational measures, internal rules, declarations for granting and withdrawing consent for processing, request for deletion and for portability of personal data by subjects of data collection, etc. Undoubtedly, this documentation will help the procedure of data processing in the field of higher education, and it will also facilitate the concerned with the code parties in the process of meeting the requirements of the GDPR.

6) Categories of personal data and / or registers containing personal data processed by the controllers / data processors who will implement the draft code

The personal data register is the set of data for identification of individuals, which the controller processes in the course of his professional duties (Feti, 2018, p. 39). For example, the categories of personal data processed by higher education institutions may be related to physical identity, health status, education, professional experience, etc., related to the delivery of educational and library services to individuals, subjected to data collection, employment and civil contractual relations to which the higher education institution is a party etc. The sectoral approach, on the basis of which the codes of conduct are supposed to be prepared and applied, requires unification of the registers with personal data and of the separate categories of data that the administrators and processors operate with (Toshkova-Nikolova, Feti, 2019, p. 321). In this regard, the draft Code of Conduct should describe the possible registers and the categories of personal data they contain, as well as the purposes and deadlines for their processing by the higher education institutions that have acknowledge it.

\section{7) Legal basis for data processing by controllers / processors of personal data who will apply the draft code}

The draft code should contain an analysis of the applicable legal bases on which the data processing operations in the field of higher education are conducted. It is also necessary to describe the technology of personal data processing, as well as to indicate how personal data is collected and stored. The decree of Art.30 of the GDPR establishes an obligation for the controllers / processors of personal data to maintain documentation, related to the personal data processed by them. Maintaining a register of processing activities is a form of reporting on the circumstances related to the processing procedures. The register is maintained in writing, including in electronic format, according to Article 30, para.3 of the GDPR. In this regard, it is necessary - the fulfillment of the obligations of the administrators to maintain a register of processing activities to be included in the code.

\section{8) Legitimate interests of the controllers / processors, where applicable}

The legal basis "legitimate interests" is one of the foundations specified in Article 6, para.1 of the GDPR, related to the quality of the data. The occurrence of at least one of them is a prerequisite for legal processing. Processing of personal data on the grounds of "legitimate interest" is permitted by the GDPR, but only if the legitimate interests of the controller / processor take precedence over the interests or fundamental rights and sovereignty of the subjects of data collection. In order to rely on this legal basis, the controller / processor should assess the required balance between his legitimate interests and the interests of the subjects of data collection. Moreover, the interest must be in accordance with the law, be real and be sufficiently specific (for example, conducting video surveillance to protect the material base of the university). In this regard, the draft Code of Conduct should define and specify the legitimate interest that is the basis for data processing in the field of higher education. It is also necessary to contain an analysis of the sense of balance and the arguments for its advantage over the interests or fundamental rights and sovereignty of the subjects of data collection.

\section{9) Application of the principles of data protection under Art. 5 of the GDPR, including the principles of conscientiousness and transparency}

This criterion requires that the written mechanisms contained in the draft Code of Conduct be applied in the activities of the administrators / processors of personal data who are using it, in order to comply with Article 
5, para.1, letter "A" of the GDPR - principle of legality, conscientiousness and transparency. The lawfulness of the processing requires compliance with all current legislation, not only that of the personal data protection (Alexandrov, 2018, p. 46). The important thing is that conscientiousness as an element of this principle requires the controller to process the data honestly and openly, as well as to provide sufficient information to the subject of data collection about the implementation of the processing activities and their objectives. Transparency, in turn, complements good faith, as its manifestation is guaranteed by the right of information of the subjects of data collection, as well as by the corresponding obligations of controllers to provide information. In this regard, the need to inform and explain to the subjects of data collection the information processed in relation to the activities carried out by higher education institutions is indispensable. It is necessary for the code of conduct to contain procedures and mechanisms for notifying subjects of data collection of their rights under the GDPR, their implementation, the context of processing, including what data processing operations are carried out in the sector concerned, what is the scope of processing. It is important that the information provided to subjects of fata collection is easily accessible and made public. The right of information of the subjects of data collection is among the fundamental rights regulated in the GDPR, which is directly related to the obligation for transparent data processing and openness in the relationship between the controller and the subject of data collection. In addition, the public should be informed about the process of accession to the Code. Promoting the code is essential to achieve a high level of data protection and reduce the risks of adverse effects to the privacy of the individuals.

\section{0) Measures, predicted to ensure the observance of the rights of the subjects of data collection}

According to Chapter Three of the GDPR, controllers are obliged to assist subjects of data collection in executing their rights. Therefore, the draft code of conduct should contain procedures and documents regarding the provision of access and control to the individuals whose data is processed. The aim is to specify the circumstances and conditions in which the subjects of data collection may fulfill their data protection rights (e.g. right of deletion, rectification, portability, restriction of processing) and to be informed. It is also necessary to introduce guarantees for the fulfillment of the obligation of the controller to take action on requests for the execution of rights by subjects of data collection. In relation to the execution of the right of access, the CPDP specifies that the Code should state the categories of individuals who have the right to access information from personal data registers, as well as the degree of such access - full or organic (CPDP. Procedures for approving, amending or supplementing a code of conduct, 2018, p.5).

\section{1) The procedure of information and protection of the children and the process of obtaining consent from parents and legal guardians}

Children are a vulnerable group on the subject of data collection and they are in need of an enhanced protection. They are entitled to special protection of personal data, as they are not sufficiently aware of the relevant risks, consequences and guarantees, as well as their rights related to the processing of personal data (Consideration 38 of the GDPR). The conditions applicable to the consent of a child in connection with the services of the information society are introduced in Article 8 of the GDPR. This decree affects only one of the cases - when the processing is based on the consent of the subject of data collection and this consent is given in an online environment, for example to create a user profile on a website (Alexandrov, 2018, $p$. 59). The age limit for the child, in connection with the granting of consent for the processing of his/her personal data, is set tentatively in the GDPR; therefore the regulation allows the national legislator to choose the age. According to Article 25v of the LPDP (The Law for Personal Data Protection), when providing services to the children's information society, administrators will have to take into account the age of the child and, depending on the circumstances, require the consent of the parent or guardian when the child is under 14 years old. Considering the lawful processing of data by higher education institutions, it is necessary in the draft code of conduct to be included information on possible cases, requiring the processing of children's data in order to assess its relevance in the field of higher education.

\section{2) The appropriate technical and organizational protection measures plan, including pseudo- domination of the data, if applicable}

The GDPR requires that personal data is processed in a way that ensures its security, including protection against unauthorized or unlawful processing, as well as against accidental loss, destruction or damage (see Article 5, paragraph 1 and Article 32 of the GDPR). In order to ensure the security of processing, the draft code should specify possible technical and organizational protection measures, as well as the conditions for their implementation. For example, the application of pseudo-metonymy and anonymization of personal data can reduce the risks for data subjects and help higher education institutions to fulfill their data protection obligations in the course of their activities. The choice of specific measures should take into account the risk analysis, the definition of security levels and the associated protection levels. 
13) The reference to the code as an appropriate guarantee in the sense of art. 46 (2), "D" of the GDPR

When transfer of data to third countries or international organizations is carried out on the basis of Article 46, para.2, letter " $D$ " of the GDPR the code should contain appropriate guarantees for the rights and sovereignity of the subjects of data collection and specify, the manner in which the recipient in a third country or international organization will apply them.

14) The procedure for notifying supervisors of personal data violation and reporting such violation to the concerned subjects of data collection

The requirement to notify the competent national supervisory authority and notifying the individuals in certain cases, when there is a breach of personal data security, is explicitly introduced in Articles 33 and 34 of the GDPR. Notification of violations should be seen as a tool to enhance compliance with data protection requirements (WP250, rev.01, 2018, p. 6). The nature of the data and the huge risks of security breaches also require that appropriate measures are taken to ensure a higher level of data protection. Therefore, the code of conduct should contain an analysis of possible situations where a violation of security may pose a risk to the rights and sovereignty of the individuals, as well as rules and procedures on intervening with possible violations of data security. Their main purpose is for the controller to manage security violations in an appropriate and timely manner, as well as to reduce or limit the impact of the breach on the subjects of data collection.

15) Extrajudicial proceedings and other procedures for resolving disputes between controllers and subjects of data collection regarding the processing of the latter

This requirement obliges the draft code to contain information on the mechanisms of settling possible disputes, related to the processing of personal data, applied by its administrators / processors. However, extrajudicial proceedings such as arbitration and mediation should not derogate the rights of the subjects of data collection appearing before the national supervisory authority or the court.

\section{6) The procedure of amending and improving the draft code of conduct}

The draft Code of Conduct should consist of a procedure for its amendment, in order to update it and in a timely manner, in order to comply with the requirements of personal data protection and regarding the specifics of the activities of controllers / processors in the field of higher education.

17) The procedure of taking appropriate action in an event of a violation of the draft code by a controller or processor

In case of violation of the requirements of the Code of Conduct by an acceding controller or processor of personal data, it is necessary that the draft code should contain written rules and procedures regarding the actions taken against them. These follow-up actions should include suspending or excluding membership from the Code from the controller or processor concerned.

\section{PROCEDURE FOR APPROVING A CODE OF CONDUCT REGARDING THE PROTECTION OF PERSONAL DATA}

The procedure for approving a code of conduct is implemented by submitting a request. With its submission, the competent, adjudicating authority is notified (the CPDP) and the beginning of the procedure for its approval, under Art. 64 - 69 of the RPCPDPIA, is initiated.

Associations and other structures representing the category of controllers / processors of personal data from the respective sector or branch have the right to initiate the planning of a code of conduct. They should consult relevant stakeholders, including subjects of data collection, when drafting a code of conduct and take into account their opinion.

The specifics of the procedure for approval of the code of conduct and the requirements regarding the content of the request are set out in Article 64, para.1 of the RPCPDPIA. It must contain the following information:

- Information about the nominator of a code of conduct (association or other authority of the respective sector, branch or category of controllers / processors for whom the code is applicable) indicating its name, address, VAT number or other unique identifier;

- Name of the code of conduct, which cannot duplicate the name of an already registered and published code of conduct; 
- The categories of controllers / processors to whom the code of conduct will apply.

The draft code of conduct whose approval is sought shall be attached to the request on paper copy and in electronic format.

According to Article 65 of the RPCPDPIA, the draft code is sent back to the depositor without consideration when:

- Is submitted by a person who has no representative authority over the administrators or processors who will implement the draft code of conduct;

- The submitter of the draft code has not consulted all stakeholders, incl. subjects of data collection, where feasible and / or no information is provided on whether the opinions provided by stakeholders during the consultation have been taken into consideration;

- CPDP is not competent according to Article 55 of the GDPR to review and approve the draft code.

The request is submitted in person at the office of the CPDP, by mail or electronically to the email of the CPDP under the Electronic Document and Electronic Certification Services Act, i.e. the request and the draft code of conduct must be in the form of electronic documents signed with an eligible electronic signature. The submitted request is dispersed to the Legal Analytical Information and Control Directorate, which verifies the compliance of the Code with the GDPR, ensuring its coordinated implementation by the controllers / processors who will implement it, the availability of appropriate guarantees of rights and the sovereignty of the individuals, including an analysis of the availability of information and evidence regarding the requirements for approval of the Code, specified in Article 66 of the RPCPDPIA. The final evaluation of the directorate is submitted to a meeting of the CPDP, which at a closed meeting pronounces a resolution by which it can:

- Return the code of conduct for amending its compliance with the GDPR if it finds non-compliance with the requirements of the regulation and / or lack of sufficient adequate guarantees for the rights and sovereignty of the individuals;

- Approves the code when it contains the specifics of the GDPR within the respective sector and fully meets the requirements of Article 64, para.3 and Article 66 of the RPCPDPIA.

The CPDP informs the nominator of the code of conduct and in case of approval, within seven days from the adoption of its decision, publishes the code of conduct in the register of codes of conduct under Art. 40 of the GDPR and sends it to the EDPB (European Data Protection Board) for publication in the register under Article 40, para. 11 of the GDPR.

When the draft Code of Conduct anticipates cross-border data processing in several EU Member States, the CPDP provides information about it to the related authorities and the EDPB through the internal market information system and applies the coherence mechanism under Article 63 of the GDPR. In this case, the CPDP cannot approve such a code before the EDPB has expressed an opinion on the compliance of the draft code with the requirements of the GDPR, respectfully of appropriate guarantees in the cases under Article 40, para.3 of the GDPR.

\section{CONCLUSION}

The Code of Conduct summarizes the basic rules of conduct regarding the protection of personal data. Undoubtedly, its adoption in the field of higher education is a matter of great practical application, as it will establish a uniform standard for the processing of personal data by higher education institutions that will apply it. The Code as a tool of data protection measures will play an essential role in the precise and effective application of the GDPR in the implementation of requirements and taking into account the specifics of the activities of higher education data processing. It would enable the management and administrative staff, as well as the data protection officials, to identify in a timely manner the risks related to data collection in higher education, as well as to take appropriate action to limit them (Prodanov, 2021, p. 178). Moreover, the benefits of the Code of Conduct are equally extensive to the subjects of data collection.

\section{REFERENCE LIST}

Aleksandrov, A. (2018). Ot 25 may 2018 godina zapochva da se prilaga Obshtiyat reglament za zashtita na 
lichnite danni. Trud i pravo (4), 44-51

Aleksandrov, A. (2018). Kakvo tryabva da znayat rabotodatelite pri obrabotvane na lichni danni na detsa. Trud i pravo (7), 58-66

Andreeva, A., Dimitrova, D. (2021). Aktualni tendentsii v zakonodatelnata uredba na vissheto obrazovanie v Bulgaria. Strategii na obrazovatelnata i nauchnata politika. Sofia : Az-Buki, God. 29 (1), $9-20$

CPDP. (2018). Criteria and procedures for approval, amendment or supplementation of a code of conduct. https://www.cpdp.bg/

Dimitrova, D. (2020). Novi momenti v administrativnia kontrol varhu deynostta na visshite uchilishta. Obshtestvo i pravo. Sofia : Sayuz na yuristite v Bulgaria (4), $73-84$

Dimitrova, D. (2016). Legal Regime of the Bulgarian High Schools from the Liberation until Present Days. Izvestya J. of Univ. of Econ. - Varna, 60, (2), 217 - 229

European Data Protection Board. (2019). Guidelines 1/2019 on codes for conduct and monitoring authorities according to Regulation 2016/679. https://www.cpdp.bg/?p=element\&aid=1213

Feti, N., Toshkova-Nikolova, D. (2020). Prilagane na zashtitata na lichnite danni. Metodiki, preporaki i prakticheski stapki. Sofia: IK"Trud i pravo“"

Feti, N. (2018). Poddarzhane na registar na deynostite po obrabotvane na lichni danni. Trud i pravo (9), 37 48

Prodanov, G. (2021). Kodeks za povedenie vav vrazka s obrabotvaneto na lichni danni v sferata na vissheto obrazovanie. Zashtitata na lichnite danni i digitalizatsiyata - predizvikatelstva i perspektivi. Varna: Nauka i ikonomika, 172-179

Standpoint of the CPDP, reg. № NDMSPO-01-697 / 27.06.2018

Standpoint of the CPDP Reg. № NDMSPO-17-723 / 2018, 22.02.2019

Toshkova-Nikolova, D., Feti, N. (2019). Zashtita na lichnite danni, Sofia: IK"Trud i pravo“

Tselkov, V., D. Petkov, G. Sredkov, P. Georgiev. (2020). Zashtita na dannite - printsipi i praktiki. Sofia: Za bukvite - O pismenehy

WP250, rev.01. (2018). ARTICLE 29 DATA PROTECTION WORKING PARTY. Guidelines on Personal data breach notification under Regulation 2016/679

Yolova, G. (2021). Za elektronnite zdravni zapisi v konteksta na zashtitata na lichnite danni. Zashtitata na lichnite danni i digitalizatsiyata - predizvikatelstva i perspektivi. Varna: Nauka i ikonomika, 76-85 